\title{
Benefits and Challenges of ICT Adoption IN Indian PDS
}

\author{
Prof. Rahul J. Jadhav', Dr. K. M. Nalawade ${ }^{2}$ \\ Associate Professor, BVDU YMIM, Karad, India ${ }^{1}$ \\ Principal, KGDBL Mahavidyalaya, Kundal, India ${ }^{2}$
}

\begin{abstract}
This paper presents the results of an exploratory study carried out to learn about the benefits and challenges of Information and Communication Technologies (ICT) public distribution system. The study investigates ICT infrastructure, software used, driver for ICT investment, perceptions about business benefits of ICT and outsourcing trends of PDS. The study provides an insight on the barriers for the adoption of ICT. Data on these aspects of ICT was collected from Fair price shops (FPS) satara (Maharashtra) districts through a survey instrument. The results of the study show that only a small number of FPS is aware of the benefits of ICT adoption. The main driving forces for ICT investment are to provide better and faster customer service and to stay ahead of the competition. Lack of internal capabilities, high cost of ICT and lack of information about suitable ICT solutions and implementation were some of the major barriers in adopting ICT. There is a need for more focus and concerted efforts on increasing awareness among FPS on the benefits of ICT adoption. The results of the study recognize the need for more training facilities in ICT for FPS, measures to provide ICT products and services at an affordable cost, and availability of free professional advice and consulting at reasonable cost to FPS. Our findings therefore have important implication for policy aimed at ICT adoption and use by PDS. The findings of this research will provide a foundation for future research and will help policy makers in understanding the current state of affairs of the usage and impact of ICT in PDS.
\end{abstract}

Keywords: PDS (Public Distribution System), ICT (Information and communication Technology) Fair Price Shop, Social Security, Essential Commodities.

\section{INTRODUCTION}

Today organizations of all types are utilizing Information and Communication Technologies (ICT) around the globe, not only for cutting costs and improving efficiency, but also for providing better customer service. Governments too, around the world, are adopting ICT to provide better services to their citizens. The adoption of ICT by organizations requires a business environment encouraging open competition, trust and security, interoperability and standardization and the availability of finance for ICT (UNCTAD 2004).

The Public Distribution System (PDS) in the country facilitates the supply of food grains and distribution of essential commodities to a large number of poor people through a network of Fair Price Shops at a subsidized price on a recurring basis. With a network of more than 4 lakh Fair Price Shops claiming to distribute annually, commodities worth more than Rs 15,000 crore to about 16 crore families, the PDS in India is perhaps the largest distribution network of its type in the world.

In today's dynamic world, the transformation of services "from Ability to Agility" can be achieved by appropriate use of Information and Communications Technology. We, at ESDS believe that in order to provide better service at grassroots level, Models of Digital Governance (eGovernance) should continuously evolve and improvise to harness the potential offered by the Information and Communication Technologies (ICTs) and deal with new realities in the area of governance.

The government of India has taken various measures to diversify the economy for sustainable development of the country and one of the major steps is to transform India into a digital India. The adoption of ICT will have significant positive consequences on PDS and consequently on the social growth of India. There is a dearth of data and research about the size and contribution of PDS towards India's social growth. Therefore, through this research, we would like to learn about the effects and usages of ICT on PDS in India and their current and future perceptions towards ICT. We hope that the findings of this research will provide a foundation for future research and will help policy makers in understanding the current state of affairs of the usage and impact of ICT on PDS in India. We collected data on the Benefits and Challenges of ICT Adoption IN PDS in India through a survey questionnaire of 94(1605) randomly selected FPS from Satara district of Maharashtra state.

\section{OBJECTIVES}

- To find out the level of usage of ICT in terms of ICT infrastructure, internet connection, IT staff etc.

- To study the status of ICT implementation in public distribution system.

- To study the problems of ICT implementation in public distribution system.

\section{RESEARCH DESIGN}

We performed the following tasks to conduct the research and determine the Benefits and Challenges of ICT adoption IN Indian PDS.

A questionnaire was prepared based on the review of current literature and the questionnaire contained 
questions related to business aspects of the user, ICT indicates that 65\% FPS owners wants deployment of ICT infrastructure, use of internet, website, drivers for ICT in PDS for enhancing the performance. Majority of the investment, barriers to ICT adoption, competition, and FPS owners suggests Marathi as a language for benefits of ICT. The questionnaire was distributed to implementation of ICT in PDS. Maintenance of the beneficiaries.

Based on the completed survey questionnaires, simple statistics were carried and logical inferences were made to determine the Benefits and Challenges of ICT Adoption IN Indian PDS.

\begin{tabular}{|l|r|}
\hline Taluka & Sample size \\
\hline Satara & 30 \\
\hline Javali & 10 \\
\hline Koregaon & 15 \\
\hline Karad & 45 \\
\hline Patan & 20 \\
\hline Phaltan & 25 \\
\hline Man & 20 \\
\hline Khatav & 25 \\
\hline Wai & 15 \\
\hline Khandala & 10 \\
\hline Mahabaleshwar & 5 \\
\hline Total & 220 \\
\hline
\end{tabular}

Table 1 Sample Selection

\section{III.RESEARCH FINDINGS}

Public distribution system (PDS) in India is one of the largest welfare institutions in the world. It represents the direct intervention of the Indian state in the food market to ensure food security, is of utmost importance. Any short comings or drawbacks in such system would result in violation of the fundamental right to food in the country. In view of this and on the basis of the observations, data analysis and interpretation researcher has made some findings and recommendations.

1. During the research it is observed that majority of the beneficiaries are educated above SSC. However it is also revealed that more than $98 \%$ beneficiaries having mobile phone in their family.

2. From the study it is found that almost all the beneficiaries are in favour of introduction of computer in public distribution system. Above $90 \%$ beneficiaries are agreed or strongly agreed with the following:

- Computer will help the better serve the customer.

- Computer will save the time.

- Computer will enable better record keeping.

- Computer will enable speedy transactions.

- Computer will ensure accuracy in transactions.

- Computer in PDS will minimize the corruption.

- Computer will increase effectiveness and efficiency of PDS.

3. Researcher also found that all the beneficiaries say that "Information and communication technology can enhance the performance of public distribution system".

4. The data collected indicates that not a single FPS is computerized with software specially designed for FPS. Very few FPS owners are using computer in their shop.

5 . The analysis of the data collected by the researcher computer is a major issue for FPS owners. Majority $80 \%$ FPS owners can't do required maintenance of the computer. If end to end computerization has to employ then $98 \%$ FPS owners want some help from the government.

6. Researcher tried to find out the present status of ICT implementation in PDS. All the distribution offices are using computer, they are making limited use of computer. They are using computer only for accounting and correspondence purpose. It is also seen that $92 \%$ respondents are not happy with the infrastructure provided for the computerization by the government.

7. Researcher also found that distribution centers don't have any future plan for further or end to end computerization of PDS. $66.7 \%$ respondents are not satisfied with the present computerization of public distribution system.

\section{IV.CONCLUSION}

1) On the basis of empirical researcher work it is concluded that absence of proper recording may result in to cheating the beneficiaries.

2) It is concluded that the customers are not satisfied with the current pubic distribution system due to their poor performance. Performance can be enhanced by implementation of ICT.

3) More than $90 \%$ stake holders (beneficiaries, FPS owners, distribution officers) responded that there should be end to end computerization in PDS. Researcher concludes that ICT implementation will definitely enhance the performance of PDS.

4) It is concluded on the basis of factual data that not a single FPS is computerized with software specially designed for FPS. All the beneficiaries wanting the computerization in FPS.

5) If end to end computerization has to employ then almost all the FPS owners want some help from the government.

6) Researcher lastly concluded that there is need of end to end computerization in Public distribution system.

\section{ACKNOWLEDGMENT}

It is matter of great pleasure to acknowledge the persons who have helped me during my research work. I consider myself fortune to have been privileged to work under the guidance of Dr. K. M. Nalawade. I express my deep sense of gratitude to him for his most valuable advice, discussions, continuous supervision and support, submitted interest scholarly guidance and encouragement throughout the tenure of research work. My thanks are due to all the respondents of the selected different categories, for their earnest cooperation and speed at which retuned the questionnaires and support me to collect requisite information for research work. Lastly, I thank all my friends and all those persons who are directly or indirectly helped me for completion of this research. 


\section{REFERENCES}

[1] Dutta, Bhaskar and Bharat Ramaswami (2001), "Targeting and Efficiency in the Public Distribution System: Case of Andhra Pradesh and Maharashtra", Economic and Political Weekly, 36 (18), 1524-1532.

[2] PUBLIC DISTRIBUTION SYSTEM IN INDIA: THE PROBLEMS AND DIMENSIONS, A Project Report submitted to Indian Institute of Information Technology, Allahabad, By Varun Malhotra ,Aditi Garg ,Aditi Dubey, Asif Nasim ,MAY-2010

[3] 5. A Study on the Effectiveness of Public Distribution System In Rural Tamilnadu, Dr. S. Nakkiran Principal (Retd.), TBML Collage, Porayar-609307 TamilNadu, December-2004.

[4] 11. Nawani, N.P (1995): "Towards Food for All: Ideas for a New Public Distribution System", Publications Division, Government of India, New Delhi.

[5] UNCTAD (2004) "ICT as an Enabler for Growth, Development and Competitiveness", Plenary session, June 17, [online], http://www.unctadxi.org/templates/Event69.aspx.

[6] Gregor, S., Fernandez, W, Holtham, D, Martin, S, Vitale, M, \& Pratt, G. (2004) "Achieving Value from ICT: Key Management Strategies", Department of Communications, Information Technology and the Arts, ICT Research Study, Canberra. FLEX Chip Signal Processor (MC68175/D), Motorola, 1996.

[7] "Use and Impact of ICT on SMEs in Oman" Rafi Ashrafi and Muhammed Murtaza Sultan Qaboos University, Oman

[8] 13. "Management of Public Distribution System", Preeti R Singh, Anmol Publications, ISBN: 8174888616.

[9] Sardesai Swati Prakash (2008), "Study of citizen centric egovernance projects in Maharashtra", $\mathrm{PhD}$ thesis, University of Pune. 